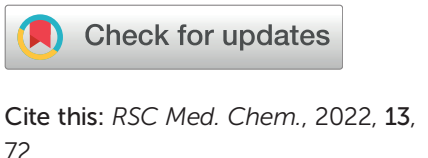
72

Received 5th August 2021, Accepted 3rd November 2021

DOI: $10.1039 / \mathrm{d} 1 \mathrm{md} 00262 \mathrm{~g}$

rsc.li/medchem

\title{
Metabolic labelling of cancer cells with glycodendrimers stimulate immune-mediated cytotoxicity $\dagger$
}

\author{
David Goyard, Peremobowei lyanu Diriwari and Nathalie Berthet (iD *
}

\begin{abstract}
The recruitment of antibody naturally present in human blood stream at the surface of cancer cells have been proved a promising immunotherapeutic strategy to fight cancer. Antibody recruiting molecules (ARMs) combining tumor and antibody binding modules have been developed for this purpose, however the formation of the interacting complex with both antibody and cell is difficult to optimize to stimulate immune-mediated cytotoxicity. To circumvent this limitation, we report herein a more direct approach combining cell metabolism of azido-sugar and bio-orthogonal click chemistry to conjugate at the cell glycocalyx structurally well-defined glycodendrimers as antibody binding module (ABM). We demonstrate that this strategy allows not only the recruitment of natural antibody at the surface of isolated cells or solid tumor models but also activate a cytotoxic response with human serum as unique source of immune effectors.
\end{abstract}

\section{Introduction}

The exploitation of endogenous antibodies naturally present in the blood stream of all individuals has recently emerged as an alternative immuno-strategy to fight cancer. ${ }^{1-3}$ To this aim, synthetic antibody recruiting molecules (ARMs) combining two binding modules, one for tumor cell (TBM) and the other for the antibody recruitment (ABM, typically dinitrophenol, $\alpha \mathrm{Gal}$ or Rha) have been demonstrated to successfully trigger immune cytotoxicity against cancer cells by CDC or ADCC mechanisms. ${ }^{4-7}$ From the first generation of ARMs to the more sophisticated antibody recruiting polymers (ARPs) ${ }^{8}$ or glycodendrimers (ARGs), ${ }^{8}$ significant advances have been made in the understanding of functional and structural requirements to improve immunological effects. If the multivalent presentation of ABM was clearly demonstrated as a key element to recruit endogenous antibodies, ${ }^{10,11}$ the major shortcoming of this approach concerns the TBM which has to ensure the binding of the cell surface without promoting internalisation to maintain the ABM exposure and accessibility at the cell surface. By doing so, the recruiting molecule can promote the formation of a reversible ternary interacting complex with antibodies and cancer cell. When suitable conditions are used to control this complex

Univ. Grenoble Alpes, CNRS, DCM UMR 5250, F-38000 Grenoble, France.

E-mail: nathalie.berthet@univ-grenoble-alpes.fr

$\dagger$ Electronic supplementary information (ESI) available. See DOI: 10.1039/ d1md00262g equilibrium process ${ }^{12}$ the immune-mediated cytotoxic effect can be activated against the cancer cell line. ${ }^{13,14}$ To avoid the utilization of TBM and the problems associated with interacting systems involving three partners, the insertion of dinitrophenol or carbohydrate haptens in the cell membrane either with a lipid anchor or by covalent conjugation was proved to be a valuable alternative as a simplified antibody recruiting system. ${ }^{8,15-19}$

In this regard, the use of well-known substrates for cell surface engineering, such as the tetraacetyl- $N$-azidoacetylmannosamine ( $\left.\mathrm{Ac}_{4} \mathrm{ManNAz}\right)$, represents a powerful and reliable method to modify the glycocalyx with unnatural recognition moieties. Once internalized, the intracellular metabolism of $\mathrm{Ac}_{4} \mathrm{ManAz}$ into azido sialic acid indeed leads to azido group expression onto extracellular glycans that can be engaged in bio-orthogonal reaction to further decorate the cell membrane by copper-free strain-promoted azide-alkyne cycloaddition (SPAAC). ${ }^{20-25}$ Several groups used similar approach to conjugate diverse haptens on the membrane of different cells to promote immune-mediated cytotoxicity. ${ }^{15,16,26}$ In this study, we reasoned that the conjugation of clustered ABM at the surface of cancer cells would represent a robust antibody recruiting approach. We recently identified an ARG composed of a tetravalent cluster of cRGD as TBM and an hexadecavalent dendrimer of Rha as $\mathrm{ABM}$ to redirect natural antibodies against cancer cells expressing $\alpha_{v} \beta_{3}$ integrins. ${ }^{11}$ This compound has been shown to stimulate immune-mediated cytotoxicity against this cell line. Among the variety of the tested compounds, we demonstrated that ARGs presenting the high rhamnose 


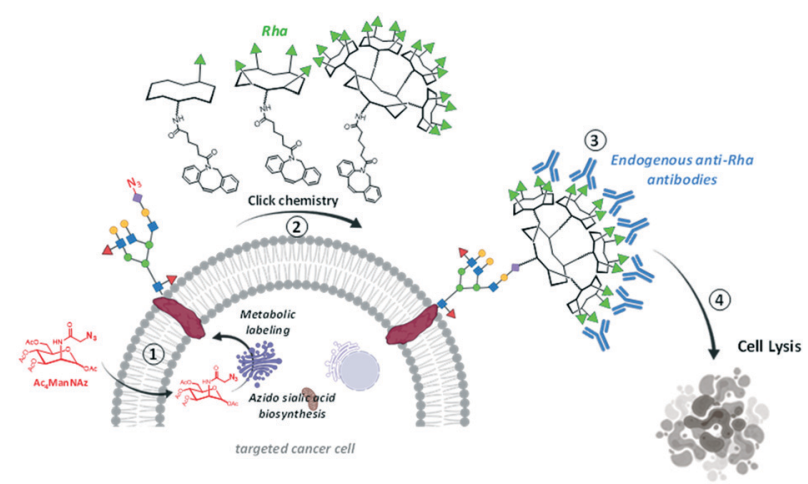

Scheme 1 Strategy combining glycometabolism and bio-orthogonal click chemistry to label cells with clustered rhamnose antigen and activate immune response against cancer cells.

valency with a precise spatial orientation were able to recruit antibodies from human serum at the surface of cancer cells and to subsequently activate an immune response. ${ }^{9}$ Herein, we exploited a metabolic labelling strategy to attach multivalent ABMs at the cell surface. To this aim, $\mathrm{Ac}_{4} \mathrm{ManNAz}$ was first delivered to BT-549 for the surface tagging with azido group (Scheme 1, step 1). The coupling with dibenzocyclooctyne (DBCO)-bearing ABMs presenting one, four or sixteen rhamnoses to the cell membrane via copperfree chemistry was performed in the second step (Scheme 1, step 2). Finally, we evaluated the recruitment of natural antibodies present in human serum (Scheme 1, step 3) and the subsequent stimulation of the immune response (Scheme 1, step 4).

\section{Results and discussion}

ABMs were synthesized as previously reported. ${ }^{11}$ Briefly, mono- 1 and tetraazido 2 cyclodecapeptides were functionalized via CuAAC using propargylated $\alpha$-L-Rha to

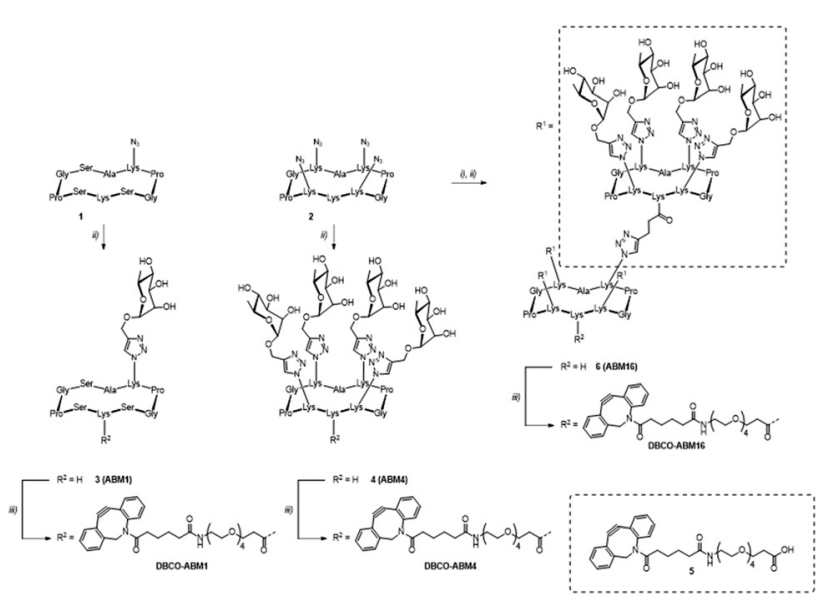

Scheme 2 Synthesis of DBCO-ABM conjugates. Reagents and conditions: i) pentynoic acid NHS ester, DIPEA, DMF, 2 h, r.t.; ii) propargyl $\alpha$-L-rhamnopyranoside or $2, \mathrm{CuSO}_{4} \cdot 5 \mathrm{H}_{2} \mathrm{O}$, THPTA, sodium ascorbate, DMF/PBS (p.H. 7.5) (1:1), 2h., r.t.; iii) 5, PyBOP, DIPEA, DMF 4 h, r.t. afford glycopeptides 3 and $\mathbf{4}$ respectively. Subsequent amide coupling between carboxylic acid-bearing DBCO derivative 5 and the free lysine side chain of compounds $\mathbf{3}$ and $\mathbf{4}$ yielded mono- and tetravalent compounds DBCO-ABM1 and DBCOABM4 respectively. Tetravalent glycocluster 4 was functionalized with pentynoic acid and subjected to another CuAAC reaction with scaffold 2 . The resulting hexadecavalent glycodendrimer $\mathbf{6}$ was finally conjugated with DBCO derivative 5 to afford DBCO-ABM16. The synthesis route is depicted in Scheme 2. Final compounds were characterized by HRMS, $1 \mathrm{H}$ NMR and analytical RP-HPLC before biological studies (see ESI $\dagger$ ).

We first determined the optimal concentration of $\mathrm{Ac}_{4}$ ManNAz for metabolic labelling with azido groups of the targeted cells. For that, the triple negative breast cancer cell line BT-549 was cultivated with various concentrations of $\mathrm{Ac}_{4}$ ManNAz for $24 \mathrm{~h}$ and the conversion in azido sialic acid was followed by treatment with the commercial DBCOPEG4-Fluor 545. The analyse by flow cytometry and confocal microscopy of the cell fluorescence enabled to determine optimal cell surface labelling for a concentration in $\mathrm{Ac}_{4} \mathrm{ManNAz}$ of $50 \mu \mathrm{M}$. Negligible fluorescence was observed for cells untreated with $\mathrm{Ac}_{4} \mathrm{ManNAz}$ confirming the absence of non-specific DBCO-dye binding to the cells (Fig. S1, ESI $\dagger$ ).

We next investigated the coupling of DBCO-conjugates (DBCO-ABM16, Fig. 1 and DBCO-ABM1-4, Fig. S2 ESI $\dagger$ ) by SPAAC to azido-bearing cells. Extracellular Rha exposure was revealed using anti-rhamnose IgM naturally present in human serum (HS). Azido tagged BT-549 cells were treated with or without DBCO-ABM (concentrations from 0.1 to 10 $\mu \mathrm{M})$ or DBCO-PEG 5 used as negative control. The SPAAC coupling of the DBCO-conjugates was evaluated by flow cytometry and confocal microscopy after successive incubations with HS and AlexaFluor488- anti-human IgM secondary antibody. A dose-dependent effect with a maximum fluorescence intensity at $10 \mu \mathrm{M}$ was observed with all DBCO-ABMs (Fig. 1a, Fig. S2, ESI $\dagger$ ) demonstrating the efficiency of the bio-orthogonal SPAAC coupling. The doseresponse curve of the fluorescence of treated cells with various concentrations of DBCO-ABM16 (Fig. S3, ESI $\dagger$ ) clearly showed a plateau at $10 \mu \mathrm{M}$. This result was confirmed by confocal microscopy of cells tagged with ABM16 (Fig. 1b) which revealed an intense fluorescence homogenously distributed around the cell surface at 5 and $10 \mu \mathrm{M}$ of DBCOconjugate, while no significant fluorescence was detected at lower concentration. Of note, no fluorescence was observed for azido-bearing cells or those treated with $10 \mu \mathrm{M}$ of DBCOPEG 5, thus indicating the absence of non-specific binding of anti-Rha antibodies.

The influence of the Rha density on the recruitment of serum antibodies was next evaluated. Cells pre-incubated with or without $\mathrm{Ac}_{4} \mathrm{ManNAz}$ were treated with $10 \mu \mathrm{M}$ of mono, tetra- and hexadecavalent DBCO-ABMs. The anti-Rha IgM recruitment was revealed by immuno-fluorescence as described earlier and analysed by flow cytometry and 


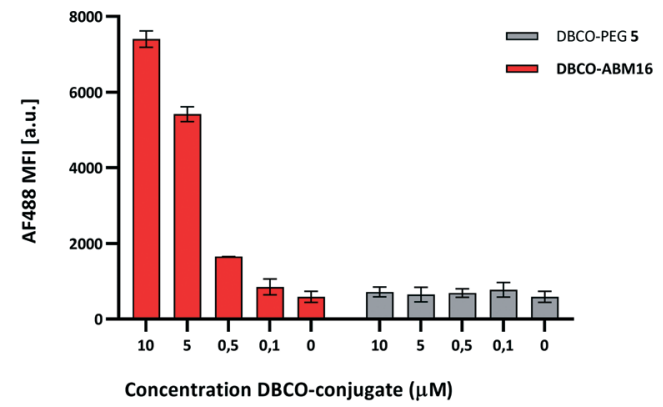

b.
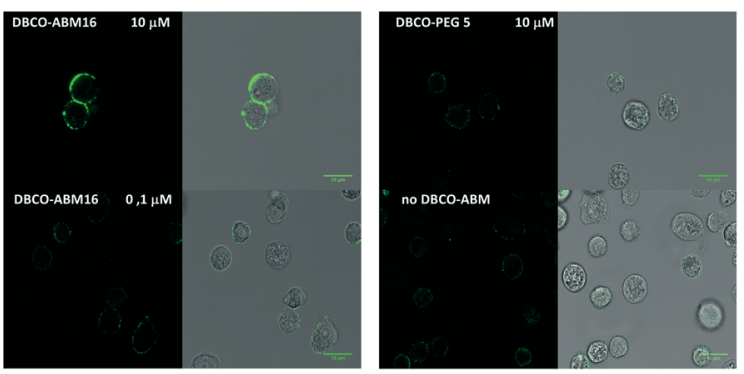

Fig. 1 DBCO-ABM16 coupling to azido groups exposed at the cell surface and anti-Rha recruitment. BT-549 cells were incubated with $\mathrm{Ac}_{4}$ ManNAz for azido labelling before treatment with DBCO-ABM16 or DBCO-PEG 5 (10-0.1 $\mu \mathrm{M})$. Azido labelled cells untreated with DBCOconjugate were used as control. SPAAC coupling of the DBCOconjugates to the cell surface was revealed using anti-Rha IgM naturally present in HS and a fluorescent secondary antibody. Cell fluorescence was analysed by flow cytometry (a. data are presented as mean \pm SD for $n=3$ measurements) and confocal microscopy (b. scale bar: $10 \mu \mathrm{m})$.

confocal microscopy. As shown by the histogram overlays reported in Fig. 2a, antibodies present in HS are efficiently recruited by all modified cell surface with DBCO-derivatives with a significantly higher efficiency for cells displaying the higher Rha density at their surface. Confocal microscopy confirmed this result since the highest fluorescence and homogenous dye labelling was observed with the ABM16 (Fig. 2b).

Interestingly, mono- and tetravalent ABM1 and ABM4 covalently anchored to the cell membrane were able to recruit antibodies present in HS while ARGs previously reported with low Rha density failed. ${ }^{11}$ These results demonstrate the interest of the metabolic labelling strategy to recruit antibody onto cell surface. In addition, flow cytometry analysis and confocal microscopy experiment with cells untreated with $\mathrm{Ac}_{4} \mathrm{ManNAz}$ or DBCO conjugates revealed negligible fluorescent intensity, thus suggesting the binding specificity of anti-Rha antibodies (Fig. 2b).

Antibody recruitment being dependent on the presence and the persistence of ABMs on the cell surface, we next studied the stability of the cell labelling with ABM. Cells pretreated with or without $\mathrm{Ac}_{4} \mathrm{ManNAz}$ were cultured for 1-8 $\mathrm{h}$ with $10 \mu \mathrm{M}$ of DBCO-ABM16 prior to being incubated with HS and the secondary antibody. The cell fluorescence was then analysed by flow cytometry. As shown in Fig. 3
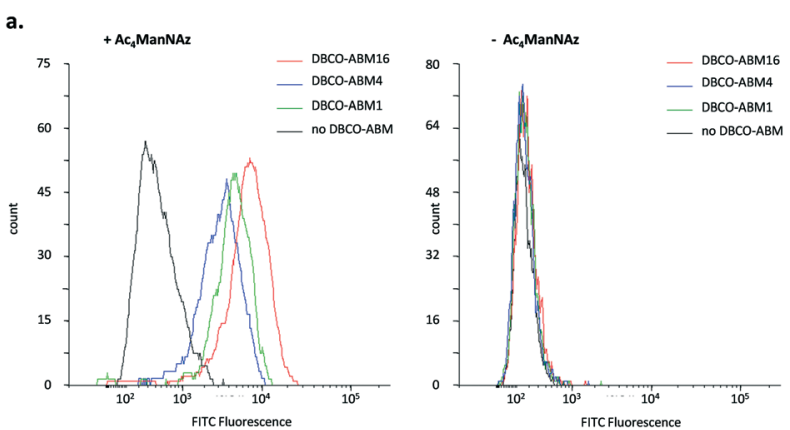

b.
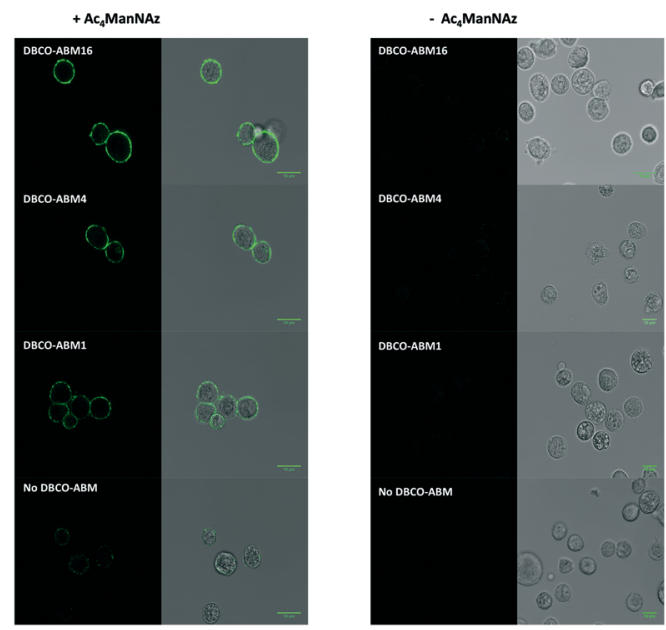

Fig. 2 a. Flow cytometry analysis of anti-Rha recruitment by labelled BT549 cells with mono-, tetra- and hexadecavalent-ABMs. Azido cells were treated with $10 \mu \mathrm{M}$ of DBCO-conjugates before incubation with HS. The antibody recruitment was revealed with AF488 conjugated secondary antibody. For both cases, non-labelled cells were used as control. b. Corresponding confocal microscopy images (scale bar: $10 \mu \mathrm{m}$ ).

persistent cell labelling with ABM16 is observed after 8 hours for cells pre-treated with $\mathrm{Ac}_{4} \mathrm{ManNAz}$ and an increase of the fluorescent intensity is also measured with increasing incubation time. These results demonstrate the stability of cell labelling with $\mathrm{ABM}$ over the time. However a fluorescent
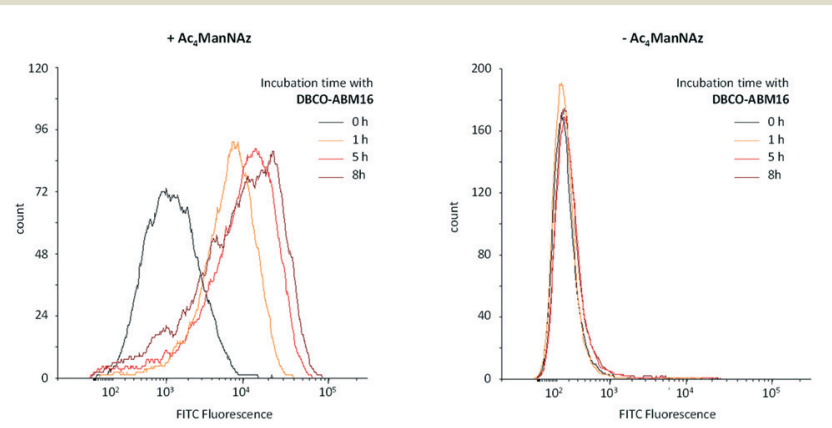

Fig. 3 Stability test of the ABM16 displayed on the cell surface. BT549 cells metabolically labelled with $\mathrm{Ac}_{4}$ ManNAz or unlabelled cells (used as negative control) were incubated for different time $(0,1,5$ and $8 \mathrm{~h})$ with DBCO-ABM16 (10 $\mu \mathrm{M}$, final concentration) prior being treated successively with $\mathrm{HS}$ and the AF488 conjugated secondary antibody. The fluorescence of the cells was analysed by flow cytometry. 

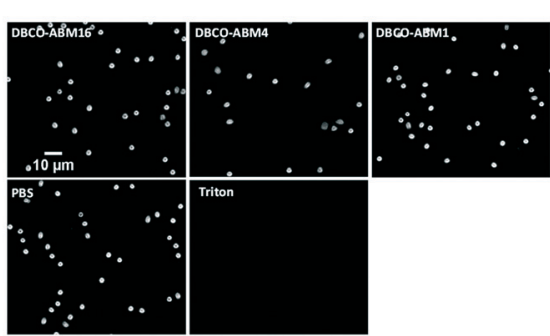

b.

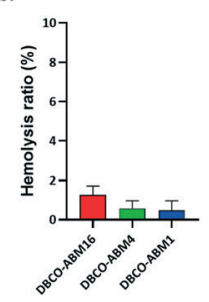

Fig. 4 In vitro human blood compatibility of DBCO-ABMs (1, 4 and 16). hRBCs were incubated with DBCO-ABMs at $100 \mu \mathrm{M}$ (final concentration). Red blood cells treatment with Triton $1 \%$ or phosphate-buffered saline (PBS) was used as positive and negative controls respectively. a. Morphology of treated hRBCs was observed under a light microscopy. b. Hemolysis ratio (\%) of hRBCs after incubation with $\mathrm{DBCO}-\mathrm{ABM}$ conjugates.

signal similar to the autofluorescence of the cells was observed for non azido-labelled cells incubated with the DNCO conjugate even after 8 hours showing one more time the specific ABM labelling for cells pre-treated with $\mathrm{Ac}_{4}$ ManNAz.

Since DBCO-ABM conjugates were attached onto the cells for antibodies recruitment in the human serum, we also evaluated their blood compatibility in an in vitro assay. This was performed by determining the effect of DBCO-ABMs (1, 4 and 16) on human red blood cells (hRBC). Like saline treatment, incubating hRBC with all DBCO-ABMs in saline did not cause detectable changes on morphology of hRBC under light microscopy even at a concentration 10 time higher than which was showing cytotoxic effect $(100 \mu \mathrm{M})$ (Fig. 4a). The hemolysis ratios for each DBCO-ABM treatments was calculated. Less than $2 \%$ of hemolysis was obtained for all conjugates, indicating a good blood compatibility of the DBCO conjugates (Fig. 4b).

We next evaluated the ability of the recruited antibodies to promote immune response leading to cancer cell destruction. Azido tagged cells treated with or without DBCO-ABMs were incubated with human serum as unique source of antibodies and protein complement and the cell viability assay which measures the complement-dependent cytotoxicity (CDC) was examined as reported previously. The cytotoxicity effect was found to increase with the ABM valency (Fig. 5), the lowest effect being observed for cells modified with the monovalent ABM1 (20\%) and the highest with the hexadecavalent ABM16 $(30 \%)$. This result is in good correlation with the antibody recruitment observed by flow cytometry. By comparison with previous studies reported by other groups, ${ }^{16,27}$ the conjugation of ABM16 promote similar cytotoxic effect at much lower concentration, thus suggesting the importance of a dense presentation in hapten to the cell surface.

In order to evaluate the ability of ABMs to recruit antibody in solid tumor context, we cultured 3D-spheroid which are commonly used as in vitro model of such tumor. ${ }^{28,29}$ Spheroids grown 4 days were cultured with or without $\mathrm{Ac}_{4} \mathrm{ManNAz}$ (untreated spheroids were used as control) prior to be treated with DBCO-ABM16 and HS (as 2D culture). As described before,

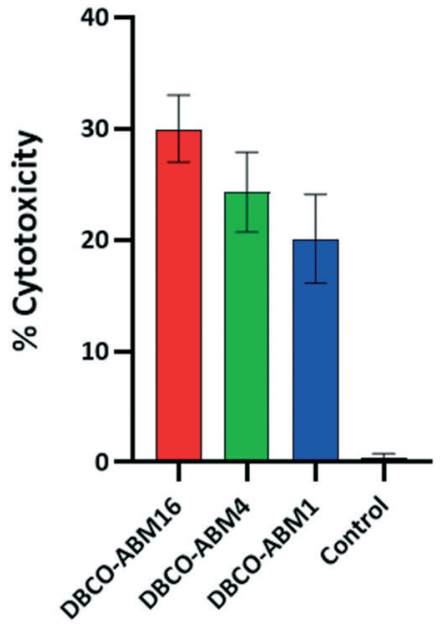

Fig. 5 Cytotoxicity of BT-549 cells induced by ABMs displayed to the cell surface following the metabolic labelling process in the presence of HS (average value of three independent experiments). Azido cells untreated with DBCO-ABMs exposed to HS were used as control. Data are presented as mean \pm SD $(n=3)$.
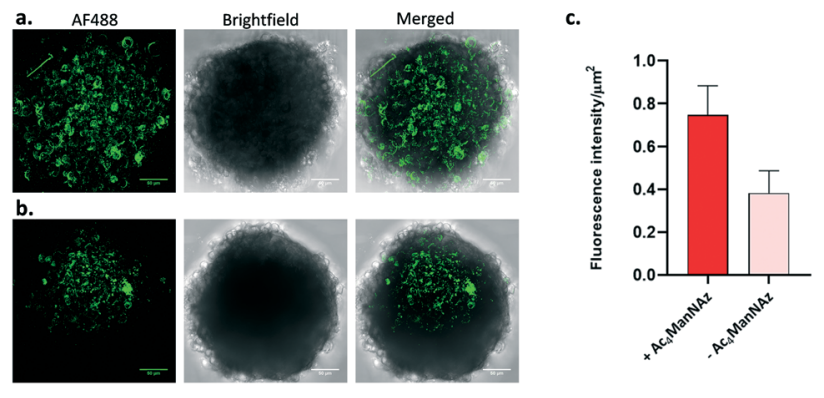

Fig. 6 Confocal microscopy images (maximum intensity projections) of BT-549 human breast cancer spheroids, cultured (a.) or without (b.) $\mathrm{Ac}_{4}$ ManNAz and treated with $10 \mu \mathrm{M}$ of DBCO-ABM16, HS and AF488secondary antibodies. Scale bar is $50 \mu \mathrm{m}$. (c.) Average AF488 fluorescence intensity of BT-549 spheroids following the same treatment as described in (a.) and (b.).

the recruitment of endogenous anti-Rha was revealed with AF488-conjugated anti-human secondary antibody.

Confocal microscopy images (Fig. 6) showed high fluorescence for spheroids cultured with $\mathrm{Ac}_{4} \mathrm{ManNAz}$ and treated with DBCO-ABM16 compared to the control spheroids. The measure of the ratio of the Fluorescence intensity reported to the spheroid surface revealed a fluorescence intensity 2 times higher for cells incubated with $\mathrm{Ac}_{4} \mathrm{ManNAz}$ compared to the control spheroids. These results clearly indicate the effectiveness of the spheroid labelling and the accessibility of Rha antigens for IgM recruitment at the cell surface to induce a targeted immune response against BT-549 tumor cells.

\section{Conclusions}

In summary, we have demonstrated the robustness of cell glycometabolism and bio-orthogonal click chemistry to 
decorate the cell glycocalyx with antibody recruiting modules. We have clearly observed that such structural modification has the ability to redirect natural antibodies present in human serum, not only against BT-549 cell line but also against 3D-spheroid model of solid tumor. More importantly, the covalent grafting of chemically well-defined ABM with high Rha density at the cell surface was found to stimulate immune-mediated cytotoxicity of BT-549. By avoiding the use of tumor binding module which significantly complicates the utilization of bimodal antibody recruiting molecules, we believe that the present strategy combining delivery of azido sugar to cancer cell and bio-orthogonal ligation of synthetic antibody recruiting modules is highly promising in the context of cancer immunotherapy. The exploitation of this approach with azido monosaccharide embedded with targeting agent and cleavable linker is however required for a selective delivery in cancer cells. We are currently investigating strategies based on the use of receptormediated endocytosis or enzyme activatable azido sugar by leveraging dysregulated mechanisms leading to enzymeoverexpression in cancer cells. The results will be reported in due course.

\section{Experimental}

\section{Materials}

Tetraacetylated $N$-azidoacetyl-D-mannosamine ( $\mathrm{Ac}_{4} \mathrm{ManNAz}$ ), Alexa-Fluor 488-coupled anti-human IgM were purchased from Fisher Scientific. All other chemical reagents were purchased from Aldrich (SaintQuentin Fallavier, France) or Acros (Noisy-Le-Grand, France) and were used without further purification. All protected amino acids and Fmoc-GlySasrin®resin was obtained fromAdvanced ChemTech Europe (Brussels, Belgium), BachemBiochimie SARL (Voisins-LesBretonneux, France) and FranceBiochem S.A. (Meudon, France). Human serum (HS) were obtained from a healthy human male donor (Etablissement Français du Sang, EFS Grenoble). Cell Cytotoxicity assay kit abcam 112118 was from Abcam. All experiments were performed in accordance with the Guidelines of the "Etablissement Français du Sang (EFS) Auvergne-Rhône Alpes 2017-2958”, and Experiments were approved by the ethics committee at the EFS AURA 21-033. Informed consents were obtained from human participants of this study. For peptides and glycopeptides, analytical RPHPLC was performed on a Waters alliance 2695 separation module, equipped with a Waters 2489 UV/visible detector. Analyses were carried out at $1.23 \mathrm{~mL} \mathrm{~min}^{-1}$ (Waters XBridge Shield RP18 $3.5 \mu \mathrm{M}, \mathrm{C} 18,100 \times 4.6 \mathrm{~mm}$ ) with UV monitoring at $214 \mathrm{~nm}$ and $250 \mathrm{~nm}$ using a linear A-B gradient (buffer A: $0.09 \% \mathrm{CF} 3 \mathrm{CO} 2 \mathrm{H}$ in water; buffer B: $0.09 \% \mathrm{CF} 3 \mathrm{CO} 2 \mathrm{H}$ in $90 \%$ acetonitrile). Preparative HPLC was performed on waters equipment consisting of a Waters 2545 controller and a Waters 2487 dual absorbance detector. Purifications were carried out at $22 \mathrm{~mL} \mathrm{~min}^{-1}$ (VP $250 \times 21 \mathrm{~mm}$ nucleosil100-7 C18) with UV monitoring at $214 \mathrm{~nm}$ and $250 \mathrm{~nm}$ using a linear $\mathrm{A}-\mathrm{B}$ gradient. ${ }^{1} \mathrm{H}$ NMR spectra were recorded on
BrukerAvanceIII $500 \mathrm{MHz}$ spectrometers and chemical shifts $(\delta)$ were reported in parts per million (ppm). Spectra were referenced to the residual proton solvent peaks relative to the signal of D2O (4.79 ppm). All mass spectrometry characterizations were performed at mass spectrometry facility, PCN-ICMG, Grenoble. ESI $\uparrow$ high resolution mass spectra of peptides and glycopeptides were measured on a LTQ Orbitrap XL spectrometer from Thermo Scientific.

\section{Synthetic procedures and characterization}

General procedure for the amide coupling of DBCO derivative 5. A solution of 5 (2 eq.), PyBOP (2 eq.) and DIPEA (4 eq.) in dry DMF $(0.5 \mathrm{~mL})$ was stirred at room temperature for 1 hour then a solution of rhamnosylated glycocluster or glycodendrimer (1 eq.) in dry DMF $(0.5 \mathrm{~mL})$ was added. The mixture was stirred at r.t. for 2 hours, diluted in $\mathrm{H}_{2} \mathrm{O}$ /TFA (99.9 : 0.1 ) and purified by semi preparative RP-HPLC. Fractions containing the product were collected and lyophilized to obtain the desired compound as a white fluffy solid.

Compound DBCO-ARM1. Prepared according to the general procedure from $3(8.5 \mathrm{mg}, 7.6 \mu \mathrm{mol})$. The crude mixture was purified (5-100\% B in $20 \mathrm{~min}$ ) to afford the title compound (9.6 mg, $5.7 \mu \mathrm{mol}, 75 \%)$. HRMS $\left(\mathrm{ESI}^{+}\right) \mathrm{m} / \mathrm{z}$ : calcd for $\mathrm{C}_{79} \mathrm{H}_{116} \mathrm{~N}_{16} \mathrm{O}_{25}[\mathrm{M}+2 \mathrm{H}]^{2+}$ : 844.4143, found 844.4176; RPHPLC: $R_{\mathrm{t}}=5.79 \mathrm{~min}(\mathrm{C} 18, \lambda=214 \mathrm{~nm}, 5-100 \% \mathrm{~B}$ in $15 \mathrm{~min})$.

Compound DBCO-ARM4. Prepared according to the general procedure from $4(11.8 \mathrm{mg}, 6.1 \mu \mathrm{mol})$. The crude mixture was purified (5-100\% B in $20 \mathrm{~min}$ ) to afford the title compound (12.3 mg, $4.9 \mu \mathrm{mol}, 81 \%$ ). HRMS (ESI ${ }^{+}$) $\mathrm{m} / \mathrm{z}$ calcd for $\mathrm{C}_{115} \mathrm{H}_{173} \mathrm{~N}_{25} \mathrm{O}_{37}[\mathrm{M}+2 \mathrm{H}]^{2+}: 1248.1207$, found 1248.1255; RPHPLC: $R_{\mathrm{t}}=6.72 \min (\mathrm{C} 18, \lambda=214 \mathrm{~nm}, 5-100 \% \mathrm{~B}$ in $15 \mathrm{~min})$.

Compound DBCO-ARM16. Prepared according to the general procedure from $6(20.0 \mathrm{mg}, 2.2 \mu \mathrm{mol})$. The crude mixture was purified ( $0-80 \% \mathrm{~B}$ in $20 \mathrm{~min}$ ) to afford the title compound (15.1 mg, $1.5 \mu \mathrm{mol}, 71 \%$ ). HRMS (ESI + ) $\mathrm{m} / \mathrm{z}$ calcd for $\mathrm{C}_{431} \mathrm{H}_{669} \mathrm{~N}_{117} \mathrm{O}_{141}[\mathrm{M}+6 \mathrm{H}]^{6+}: 1623.3124$, found 1623.3195; RPHPLC: $R_{\mathrm{t}}=7.59 \min (\mathrm{C} 18, \lambda=214 \mathrm{~nm}, 0-80 \% \mathrm{~B}$ in $15 \mathrm{~min})$.

\section{Instrumentation}

Flow cytometry analysis was performed on a BD LSR FORTESSA Flow cytometer (laser excitation at $\lambda=488 \mathrm{~nm}$, emission bypass filter at 525/50).

Confocal microscopy images of $2 \mathrm{D}$ and $3 \mathrm{D}$-cultures were taken with a TCS SP8 CSU Leica (HC PL APO CS2, 40×/1.30 OIL, laser excitation at $\lambda=488 \mathrm{~nm}$ and fluorescence emission collected between $\lambda=495$ and $545 \mathrm{~nm}$ ). Images were processed using ImageJ software.

The solution-absorbance in microplates was read on a POLARstar Omega plate reader (BMG labtech).

\section{Cell culture method}

BT-549 cells were purchased from ATCC and were cultured in RPMI 1640 medium supplemented with 10\% fetal bovine serum, $100 \mu \mathrm{g} \mathrm{mL}^{-1}$ streptomycin and $100 \mathrm{U} \mathrm{mL}^{-1}$ penicillin (all from Sigma-Aldrich). Cells were maintained in an 
incubator at $37{ }^{\circ} \mathrm{C}$ in a $5 \% \mathrm{CO}_{2}$ humidified atmosphere and allowed for downstream experiment until 90\% confluency.

\section{Determination of the optimal concentration of $\mathrm{Ac}_{4} \mathrm{ManN}_{3}$ for in vitro metabolic cell labelling}

BT-549 cells were seeded at a density of about 150000 cells per well in 6-well plates and cultured for $24 \mathrm{~h}$ in the medium described in the cell culture method section. Various dilutions of $\mathrm{Ac}_{4} \mathrm{ManNAz}$ were prepared and add directly to the culture medium to get final concentrations from $1 \mu \mathrm{M}$ to $50 \mu \mathrm{M}$ and the culture was continued for $48 \mathrm{~h}$. The culture medium was then removed and cells were washed 3 times with PBS prior to be incubated with $50 \mu \mathrm{M}$ DBCO-PEG 4 -Fluor 545 diluted in HBSS for $1 \mathrm{~h}$ at $37^{\circ} \mathrm{C}$ (50 mM stock solution in DMSO was prepared). Control cells without azido sugar received the same amount of DMSO. Cells were washed again 3 times with PBS then were detached by treatment with 0.5 $\mathrm{mL}$ per well of trypsin-EDTA for $5 \mathrm{~min}$ at $37^{\circ} \mathrm{C}$. Afterwards, the harvest cells were centrifuged, washed with $1 \mathrm{~mL}$ of PBS and resuspended in $500 \mu \mathrm{L}$ of PBS for analysis by flow cytometry.

\section{In vitro coupling of DBCO-ARMs to azido labeled cells and antibody recruitment analysis}

BT-549 cells (150000 cells per well in 6-well plates) were cultured for $24 \mathrm{~h}$ prior to be incubated with $50 \mu \mathrm{M} \mathrm{Ac} 4^{-}$ ManNAz as described above. After culture medium removing, cells were washed 3 times with PBS then the copper-free click chemistry of azido-labeled cells with various concentrations of each DBCO-ABMs in HBSS $(0 \mu \mathrm{M}, 0.1 \mu \mathrm{M}, 0.5 \mu \mathrm{M}, 5 \mu \mathrm{M}$ and $10 \mu \mathrm{M}$ ) was performed for $1 \mathrm{~h}$ at $37^{\circ} \mathrm{C}$. Cells were then washed twice with PBS and were detached with trypsin-EDTA as described previously. Washed cells were then incubated with 50\% human serum in PBS-1\% BSA for $1 \mathrm{~h}$ at $37{ }^{\circ} \mathrm{C}$. Following 1 wash with PBS-1\% BSA, cells were incubated with 1:400 AF488-conjugated goat anti-human antibody for $1 \mathrm{~h}$ at $37^{\circ} \mathrm{C}$. Finally, the cells were washed and resuspended in 500 $\mu \mathrm{L}$ PBS and analyzed for FITC intensity by flow cytometry and confocal microscopy.

\section{Complement-mediated cytotoxicity}

BT-549 cells were plated onto the 96-well plate at the concentration of 20000 cells per well and left to adhere for $24 \mathrm{~h}$ prior to be incubated with $50 \mu \mathrm{M} \mathrm{Ac}{ }_{4} \mathrm{ManNAz}$ for $48 \mathrm{~h}$ at $37{ }^{\circ} \mathrm{C}, 5 \% \mathrm{CO}_{2}$. Plates were then washed twice with PBS and click chemistry with $10 \mu \mathrm{M}$ DBCO-ABMs in HBSS was performed for $1 \mathrm{~h}$ at $37^{\circ} \mathrm{C}$. Solution was then removed and cells were incubated with $100 \mu \mathrm{L}$ of HS 50\% in HBSS for $2 \mathrm{~h}$ at $37{ }^{\circ} \mathrm{C}$. Subsequently, $20 \%(\mathrm{v} / \mathrm{v})$ abcam reagent was added and the plates were further incubated for $3 \mathrm{~h}$ at $37{ }^{\circ} \mathrm{C}, 5 \%$ $\mathrm{CO}_{2}$. The plates were then read at $\mathrm{OD}_{570}$ to $\mathrm{OD}_{605}$ on microplate reader. The percentage of cell cytotoxicity was calculated using the following formula:

$$
\text { \%cytotoxicity }=\left[1-\left(R_{\text {sample }}-R_{\mathrm{o}}\right) /\left(R_{\mathrm{ctrl}}-R_{\mathrm{o}}\right)\right] \times 100
$$

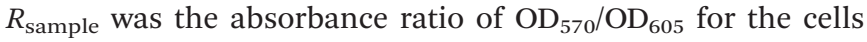
labelled with ARMs and incubated with HS.

$R_{\text {ctrl }}$ was the absorbance ratio of $\mathrm{OD}_{570} / \mathrm{OD}_{605}$ for unlabelled cells incubated with HS.

$R_{\mathrm{O}}$ was the averaged background (non-cell control) absorbance ratio $\mathrm{OD}_{570} / \mathrm{OD}_{605}$.

\section{BT-549 tumor spheroids}

Spheroids were generated by plating BT- 549 cells at 5000 cells per well into ultralow adherence-96-well plates (Corning). Spheroids grew in complete medium as in $2 \mathrm{D}$-cultures in the final volume of $200 \mu \mathrm{L}$. After $72 \mathrm{~h}$, spheroids were treated with $50 \mu \mathrm{M} \mathrm{Ac}{ }_{4} \mathrm{ManNAz}$ and $10 \mu \mathrm{M}$ DBCO-ABMs in the same manner as in 2D-cultures. Spheroids were imaged using confocal microscope (TCS SP8 CSU, Leica, laser excitation at $\lambda=448 \mathrm{~nm}$ and fluorescence emission collected between $\lambda=$ 495 and $545 \mathrm{~nm}$ ) equipped with a $40 \times$ objective and analysis was performed with the ImageJ software.

\section{Human red blood cell hemolysis assay}

All experiments were performed in accordance with the Guidelines of the "Etablissement Français du Sang (EFS) Auvergne-Rhône Alpes 2017-2958", and Experiments were approved by the ethics committee at the EFS AURA 21-033. Informed consents were obtained from human participants of this study. Human red blood (hRBC) were obtained by centrifugation of $2 \mathrm{~mL}$ of whole blood collected in heparin tubes, from healthy donors (EFS Grenoble) at $800 \mathrm{~g}$ for 10 min at room temperature. After removal of the plasma, hRBC were further purified by washing three times with PBS and resuspended in PBS at a final concentration of $2 \%$. The hRBC suspensions $(180 \mu \mathrm{L})$ were incubated with $20 \mu \mathrm{L}$ of DBCOABM 1, 4 or 16 ( $1 \mathrm{mM}$ in PBS) while parallel assays were performed using $\mathrm{PBS}$ as negative control and a $1 \%(\mathrm{w} / \mathrm{v})$ solution of Triton X-100 as positive control. After incubation at $37{ }^{\circ} \mathrm{C}$ in $5 \% \mathrm{CO}_{2}$ for $2 \mathrm{~h}$, each sample was centrifuged for $10 \mathrm{~min}$ at $800 \mathrm{~g}$ and $100 \mu \mathrm{L}$ of the supernatant was transferred to a 96-well microplate. Absorbance at $540 \mathrm{~nm}$ was measured using a microplate reader and the results were expressed as a percentage of hemoglobin released relative to the positive control. All treatments were performed in triplicates and the hemolysis ratio (\%) was calculated using equation:

$$
\begin{aligned}
& \text { Hemolysis ratio }(\%) \\
& \qquad=\frac{A(\text { sample })-A(\text { negative control })}{A(\text { positive control })-A(\text { negative control })} \times 100
\end{aligned}
$$

The integrity of the precipitated hRBC was checked by morphological observations under light microscopy.

\section{Conflicts of interest}

There are no conflicts to declare. 


\section{Acknowledgements}

This work was supported by CNRS, Université Grenoble Alpes, ICMG FR 2607, the French ANR project Glyco@Alps (ANR-15IDEX-02), Labex ARCANE and CBH-EUR-GS (ANR-17-EURE0003). We acknowledges the European Research Council Consolidator Grant "LEGO" (647938). We thank Cecile Cottet (LBFA, Grenoble) for confocal microscopy experiments, the data analysis and for giving access to flow cytometer.

\section{References}

1 K. Sasaki, M. Harada, Y. Miyashita, H. Tagawa, A. Kishimura, T. Mori and Y. Katayama, Chem. Sci., 2020, 11, 3208.

2 B. Lake, N. Serniuck, E. Kapcan, A. Wang and A. F. Rullo, ACS Chem. Biol., 2020, 15, 1089.

3 H. Hong, C. Li, L. Gong, J. Wang, D. Li, J. Shi, Z. Zhou, Z. Huang and Z. Wu, Chem. Sci., 2021, 12, 4623.

4 P. J. McEnaney, C. G. Parker, A. X. Zhang and D. A. Spiegel, ACS Chem. Biol., 2012, 7, 1139.

5 P. J. McEnaney, C. G. Parker and A. X. Zhang, in Annu. Rep. Med. Chem., 2017, p. 481.

6 R. T. C. Sheridan, J. Hudon, J. A. Hank, P. M. Sonde and L. L. Kiessling, ChemBioChem, 2014, 15, 1393-1398.

7 S. Achilli, N. Berthet and O. Renaudet, RSC Chem. Biol., 2021, 2, 713.

8 A. Uvyn, R. De Coen, M. Gruijs, C. W. Tuk, J. De Vrieze, M. van Egmond and B. G. De Geest, Angew. Chem., 2019, 131, 13122.

9 B. Todaro, S. Achilli, B. Liet, E. Laigre, C. Tiertant, D. Goyard, N. Berthet and O. Renaudet, Biomater. Sci., 2021, 9, 4076.

10 A. Uvyn and B. G. De Geest, ChemBioChem, 2020, 21, 3036.

11 B. Liet, E. Laigre, D. Goyard, B. Todaro, C. Tiertant, D. Boturyn, N. Berthet and O. Renaudet, Chem. - Eur. J., 2019, 25, 15508.
12 E. F. Douglass, C. J. Miller, G. Sparer, H. Shapiro and D. A. Spiegel, J. Am. Chem. Soc., 2013, 135, 6092.

13 C. B. Calson, P. Mowery, R. M. Owen, E. C. Dykhuizen and L. L. Kiessling, ACS Chem. Biol., 2007, 2, 119.

14 A. F. Rullo, K. J. Fitzgerald, V. Muthusamy, M. Liu, C. Yuan, M. Huang, M. Kim, A. E. Cho and D. A. Spiegel, Angew. Chem., Int. Ed., 2016, 55, 3642.

15 A. Uvyn, R. De Coen, O. De Wever, K. Deswarte, B. N. Lambrecht and B. G. De Geest, Chem. Commun., 2019, 55, 10952.

16 S. Li, B. Yu, J. Wang, Y. Zheng, H. Zhang, M. J. Walker, Z. Yuan, H. Zhu, J. Zhang, P. G. Wang and B. Wang, ACS Chem. Biol., 2018, 13, 1686.

17 C. E. Jakobsche, C. G. Parker, R. N. Tao, M. D. Kolesnikova, E. F. Douglass and D. A. Spiegel, ACS Chem. Biol., 2013, 8, 2404.

18 B. Lin, X. Wu, H. Zhao, Y. Tian, J. Han, J. Liu and S. Han, Chem. Sci., 2016, 7, 3737.

19 X. Li, X. Rao, L. Cai, X. Liu, H. Wang, W. Wu, C. Zhu, M. Chen, P. G. Wang and W. Yi, ACS Chem. Biol., 2016, 11, 1205.

20 N. J. Agard, J. A. Prescher and C. R. Bertozzi, J. Am. Chem. Soc., 2004, 126, 15046.

21 E. M. Sletten and C. R. Bertozzi, Acc. Chem. Res., 2011, 44, 666-676.

22 J. C. Jewett and C. R. Bertozzi, Chem. Soc. Rev., 2010, 39, 1272-1279.

23 Y. Takayama, K. Kusamori and M. Nishikawa, Molecules, 2019, 24, 172.

24 A. Mongis, F. Piller and V. Piller, Bioconjugate Chem., 2017, 28, 1151.

25 H. Wang and D. J. Mooney, Nat. Chem., 2020, 12, 1102.

26 S. H. Park, H. Jung, H. Lee, T. M. Kim, J. W. Cho, W. D. Jang, J. Y. Hyun and I. Shin, Chem. Commun., 2020, 56, 10650.

27 X. Li, X. Xu, X. Rao, Y. Tian and W. Yi, Carbohydr. Res., 2017, 452, 25.

28 C. J. Lovitt, T. B. Shelper and V. M. Avery, Biology, 2014, 3, 345.

29 D. Anton, H. Burckel, E. Josset and G. Noel, Int. J. Mol. Sci., 2015, 16, 5517. 